\title{
The Merit of Alternative Messenger RNA Splicing as a New Mine for the Next Generation Ovarian Cancer Biomarkers
}

\author{
Jean-Philippe Brosseau and Sherif Abou-Elela \\ Additional information is available at the end of the chapter \\ http://dx.doi.org/10.5772/53976
}

\section{Introduction}

In this review, we discuss the merit of splicing isoforms as a source of biomarkers for ovarian cancer with a special focus on features that distinguish splice variants from global gene expression based markers. Key examples demonstrating the usefulness of alternative splicing (AS) as markers of ovarian cancer are described.

Ovarian cancer is a low incidence cancer with high mortality rate [1]. The asymptomatic nature of this cancer and the late stage diagnosis of most tumors are the reasons for ineffective surgery and chemotherapy [2]. In this sense, intensive research aim at increasing overall patient survival and quality of life by providing biomarkers for 1) early detection and 2) prediction of chemotherapy response and/or suggestion of alternative strategies. CA-125 is a glycoprotein that is usually expressed in a variety of epithelial cells and its serum level rise up in advance ovarian cancer [3]. However, its use as an early detection marker or as a tool to screen the general population has not been approved so far [4,5]. CA-125 level is helpful in treatment-decision making but do not retain the capacity to improve overall survival and quality of life [6,7]. Clearly, there is still great need for biomarkers or combination of biomarkers that could positively identify early ovarian cancer lesions with great certainty or increase patients' survival.

Genome-wide mRNA profiling presents an opportunity to rapidly identify RNA markers. Microarray platform has been applied in numerous occasions to provide gene expression signature correlating prognosis or indicative of chemotherapy response (review in [8]). However, the nature of the platform used to carry the experiments and the analysis methods and sample sets makes inter-laboratory comparison very difficult and finding reliable mark- 
ers complicated. Indeed, a meta-analysis regrouping 829 samples fails to demonstrate the predictive power of 16 individual gene expression signatures [9]. Consequently, very few microarray markers reached the clinic. In contrast, high-throughput protein signature based on mass spectrometry platform appears to have much more overlap in the peaks found by different experimental studies [10]. However, the pace by which protein biomarkers are translated into clinical setting is relatively slow [11]. Clearly, there is a need for novel methodology to discover ovarian cancer biomarkers that can yield reliable results and produce tests that could be quickly integrated in normal clinical setting. In this chapter, we discuss the potential of splice variant annotations as a tool for the discovery of ovarian cancer markers and discuss the challenges and promises of this hidden mine.

\section{Pre-mRNA splicing mechanism and regulation}

Transcription of messenger RNA (mRNA) is the first step of converting the DNA code into functional proteins. This process was often seen as a linear cascade of events that include mRNA capping [12], splicing [13], polyadenylation [14], export to the cytoplasm [15] and translation [16] to produce a single protein. However, in reality a single pre-mRNA can produce many mRNAs through the process of AS and this in turn lead to the production of several proteins from a single gene. Splicing is the process by which the protein coding exons (typically hundreds of nucleotides in length) are joined together after the removal of large non-coding introns (typically thousands of nucleotides in length) to form the coding sequence. In some genes, this process leads to one outcome and thus named constitutive (Fig. 1.) but in most cases it leads to more than one outcome and thus called alternative (Fig. 2). Both processes are mediated by the spliceosome, specialized machinery that recognizes consensus RNA sequences $[13,17]$. The spliceosome component U1snRNP binds the 5 ' splice site (5'ss), the splicing Factor 1 (SF1) binds the branch point site (BPS) adenine, U2 auxiliary factor $65 \mathrm{kDa}$ subunit (U2AF65) binds the poly-pyrimidine tract (PPT) and U2 auxiliary factor $35 \mathrm{kDa}$ subunits (U2AF35) binds the 3' splice site (3'ss) (Fig. 1A). The last two component are further replaced by U2snRNP and following complex base-paring rearrangements and RNA-protein interactions involving hundreds of protein, the spliced mRNA, the intron by-product and the spliceosome component are release [17]. Chemically speaking, the splicing reaction proceeds in two trans-esterification steps (Fig. 1B). The first step involved the attack by the 2 ' hydroxyl of the branch point adenine on the phosphate at the 5'ss, releasing at the same time the $3^{\prime}$ end of the mRNA. The second step involved the attack by one of the hydroxyl of the terminal phosphate on the phosphate at the 3'ss, liberating the intron in the form of a lariat. This cycle of spliceosome assembly/disassembly is repeated for every intron of a gene on the nascent RNA transcript [18].

When the splice site for some exons become weak or introns with suboptimal sequence exist splicing may become less accurate and may depend on the factors that influence the splicing of competing exons and consequently produce mRNA versions with different exon pairs. AS affected the majority of multi-exons genes and is believed to be the principal driver of proteome diversity [19]. As illustrated in figure 2, two 5'ss can compete for a single 3'ss or inversely, two 3'ss can compete for a single 5'ss. These type of alternative splicing events (ASEs) are referred to alternative 5' (alt5', Fig. 2A) and alternative 3' (alt3' Fig. 2B), respectively. The most frequent 
type of ASE in human is the full skipping of an exon (cassette exon, Fig. 2C). Some exons are also skipped as a bloc (multiple cassette exon, Fig. 2D) or mutually exclusive (Fig. 2E). AS could also be coupled to others regulatory mechanisms such as polyadenylation [14] (Fig. 2F). In this case, the resulting mRNA exhibits a different $3^{\prime}$ untranslated region (UTR), which is further subjected to different regulation by small non-coding RNA (e.g. microRNA). In about 1 out of 3 cases, AS decision introduces a sequence containing premature stop codon [20]. In these cases, the resulting mRNA is flagged to be degraded by the non-sense mediated decay machinery creating an efficient mechanism that control gene expression post-transcriptionally [21] (Fig. $2 \mathrm{G})$. In some cases, ASE occurs outside the coding region and influence regulatory sequence in the UTR [22]. These different forms of splicing isoforms should not be confused with those generated by alternative transcription start site where a single gene might transcribe from different promoters (Fig. $2 \mathrm{H}$ ). In this case, and unlike alternative splicing, there is little chance that the isoform will have different protein sequence unless a new protein-coding exon is added in frame for translation initiation.

\section{A}

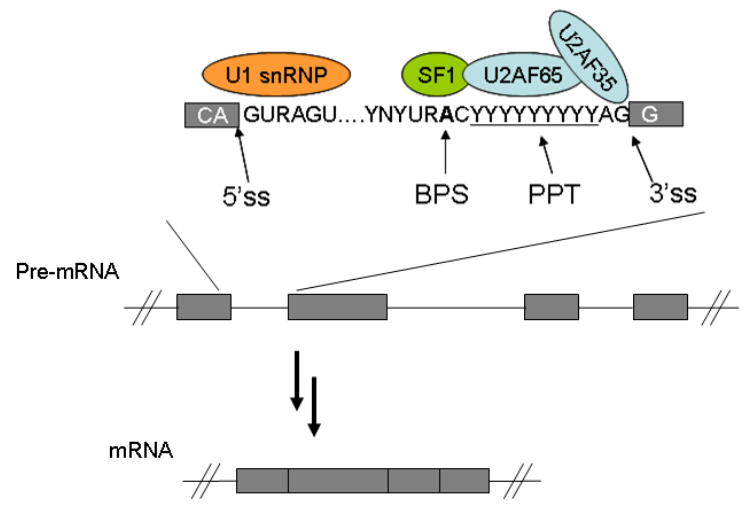

B

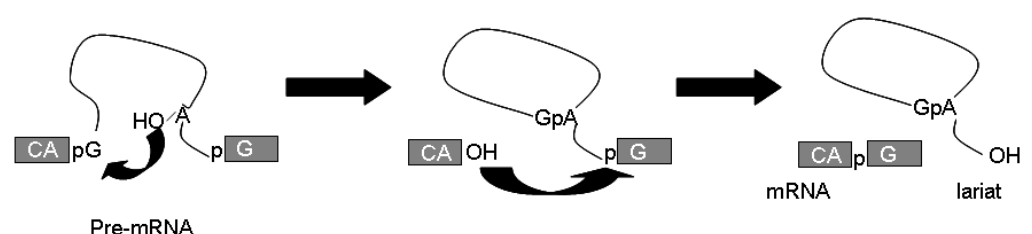

Figure 1. Constitutive splicing. A) Consensus splicing sequences. The 5'ss, BPS, PPT and 3'ss are represented and are binds by U1 snRNP, SF1, U2AF65 and U2AF35, respectively. B) Splicing reaction. The first step involved the attack by the $2^{\prime}$ hydroxyl of the branch point adenine on the phosphate at the 5'ss, releasing at the same time the 3 'end of the mRNA. The second step involved the attack by one of the hydroxyl of the terminal phosphate on the phosphate at the 3 'ss, liberating the intron in the form of a lariat. 
A

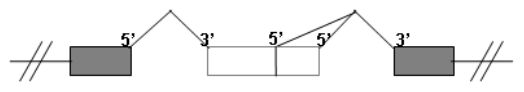

B

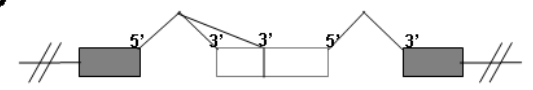

C

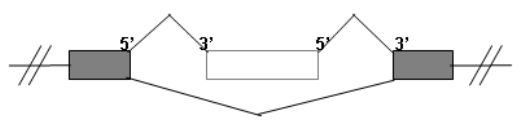

D

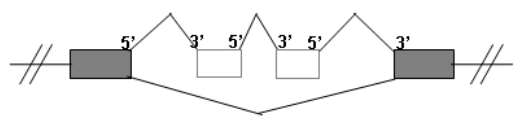

E

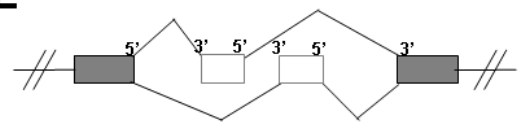

$\mathbf{F}$

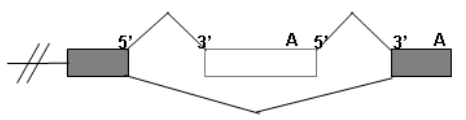

G

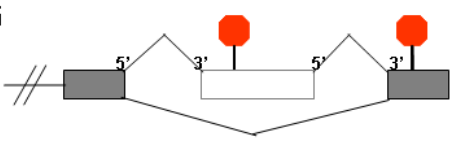

$\mathrm{H}$

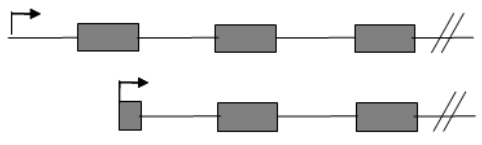

$=$ stop codon

Figure 2. Alternative splicing may take many different forms. A) Alt5'. B) Alt3'. C) Cassette exon. D) Multiple cassette exons. E) Mutually exclusive exons. F) Coupled to alternative polyadenylation. G) Coupled to NMD. H) Alternative transcription initiation. Gray boxes = constitutive exons; white boxes = alternative exons; $5^{\prime}=5^{\prime}$ splice site; $3^{\prime}=3^{\prime}$ splice site; $A=$ polyadenylation site.

ASEs are normally associated with low sequence conservation near the splice site and instead are usually linked to RNA binding motifs that may enhance or repress exon inclusion [23,24]. Motifs that enhance exon inclusion often recruit splicing factors like the SR protein family, which in turn interact with the spliceosome via an arginine serine rich domain to increase weak 5'ss and 3'ss recognition [25] (Fig. 3A). On the other hand, splicing motifs that promotes exon exclusion by binding members of the hnRNP family oligomerized through exon [26], block UsnRNA recruitment [27] or loop out the alternative exon [28] (Fig. 3B to D). Similarly, sequence motifs in intron may bind to SR or hnRNP proteins to influence splicing, but in this case, the SR proteins results in exon exclusion and hnRNP in exon inclusion. This is most likely because hnRNPs define intronic region and SR protein define exons location. Usually, these different enhancers and repressor protein families work together to define the final outcome of any ASEs (Fig. 3E) [29,30]. One of the most conserved intronic motif downstream of alternative exons is the UGCAUG motif [31,32], which bind the tissue-specific splicing factors family RBFOX. In general it is suggested that tissues specific splicing factors favor exon inclusion when bound to introns downstream of alternative exons and exclusion when bound upstream. This rule is beginning to be appreciated for several splicing factor such as Celf [33], epithelialspecific regulatory protein [34], Nova [35] and RBFOX [36] (Fig. 3F). 
A

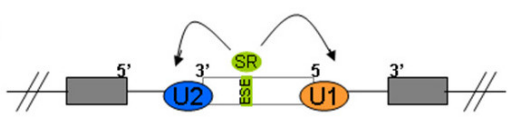

B

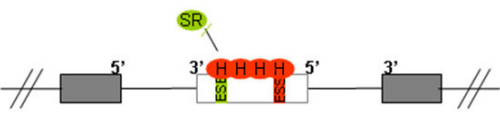

C

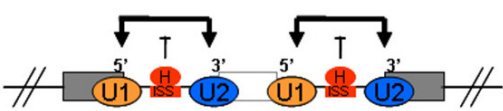

D

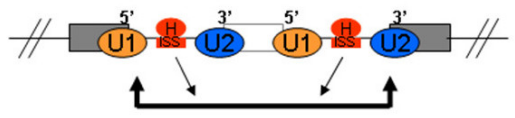

E

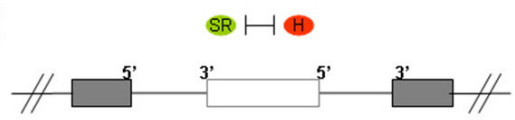

F

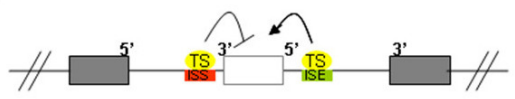

(U1) $=\mathrm{U} 1 \mathrm{snRNP}$

(U2) $=U 2 \operatorname{snRNP}$

$=$ hnRNP TS $=$ Tissu -specific splicing factor

Figure 3. Schematic representation of the different mechanisms regulating alternative splicing. A) SR protein bind to exonic splicing enhancer (ESE) and favor exon inclusion by recruting U1snRNP to 5'ss or U2 snRNP to 3'ss. B) HnRNPs binding to exonic splicing silencer (ESS) and subsequent $3^{\prime}$ to $5^{\prime}$ oligomerization through exon favor exon exclusion by blocking SR protein access to their exonic splicing enhancer (ESE). C) Intronic splicing enhancer (ISE) binding of hnRNP interferes with intron definition and favor exon definition. D) HnRNP intron looping out. E) SR protein and hnRNPs functional antagonism. F) Tissu-specific splicing factor tend to favor exon inclusion when bound to intronic splicing silencer (ISS) in intron downstream of alternative exon and exclusion when bound upstream. Gray boxes = constitutive exons; white boxes = alternative exons; $5^{\prime}=5^{\prime}$ splice site; $3^{\prime}=3^{\prime}$ splice site.

\section{The advantage of alternative splicing as a source of ovarian cancer biomarker}

Analysis of the ovarian cancer proteome using mass spectrometry is undoubtedly the most direct approach for the identification of biomarkers that could be readily implemented in the clinic. However, the difficulty generating specific antibodies for the large number of potential markers generated via this approach makes marker validation very difficult. In contrast, the validation of nucleic acid markers generated through microarray or deep-sequencing screen is fairly simple and is often achieved by polymerase chain reaction (PCR) [34,37]. Furthermore, the function of these potential markers can easily be verified through the knockdown of gene expression using RNA interference (RNAi) strategies [38]. However, scoring global changes in gene expression as markers for ovarian cancer limits the assay to 25000 genes in the genome, while it is estimate that the human cells contains at least $>100000$ proteins. This limitation is no longer an issue when we consider the expression of specific splice variants, the number of which equal or exceeds the number of cellular proteins [39]. In addition, it is much easier to predict the function of an alternative splice variant than predicting the function of a peptide marker. For examples, while the role of the well established markers CA-125 remain unclear after 25 years of research [40], one could easily predict the function of a marker by the protein domain eliminated or included through AS as is the case of the tyrosine kinase SYK. In this case, exon skipping remove a nuclear localization domain leading to the accumulation of protein in the 
cytoplasm, elegantly explaining the lost of nuclear function associated with cancer [38]. Predicting the impact of AS is particularly attractive for biomarkers development when the alternative exon encodes a plasma transmembrane domain or an extracellular protease cleavage site [41]. In these cases, one would be able to predict whether the cancer associated marker leads to an increase or decrease in the secretion of membrane anchored protein, an information that is difficult to obtain using global gene expression profiles.

\section{The challenges of detecting splicing isoforms}

Examples of alternatively spliced genes are steadily accumulating in the literature for more than 20 years and the discovery rate was greatly accelerated by recent technological advances like transcriptome sequencing techniques. Indeed, while early estimation of alternatively spliced genes based on Northern-Blots and endpoint RT-PCR were around 5\% of the human genome, transcriptome sequencing revealed ASEs in $95 \%$ of the human genes with multiple introns [39]. Different techniques have different capacity to illustrate the number of ASEs (see Table 1) and detecting splice variants remained difficult to detect for many years, which explains the reason they are not regularly considered as a source of biomarkers by most clinicians.

\begin{tabular}{|c|c|c|c|}
\hline Technique & Throughput & Advantages & Limitations \\
\hline \multirow[t]{3}{*}{ Northern-Blot } & Low & No amplification & Labour-intense \\
\hline & & Several isoforms can be & Large amount of RNA needed \\
\hline & & detected in a single sample & Restricted by gel resolution \\
\hline \multirow[t]{6}{*}{ Endpoint RT-PCR } & Low to medium & Considered as the gold & Labour-intense if polyacrylamide \\
\hline & & standard for validation & gels are used to separate PCR \\
\hline & & Results easy to analyze & products \\
\hline & & Throughput is enhanced when & Low quantitative range \\
\hline & & coupled to capillary & Restricted by gel resolution \\
\hline & & electrophoresis & \\
\hline \multirow[t]{4}{*}{ Real-time PCR } & Low to medium & Provided already validated & Custom primer design \\
\hline & & data & often needed \\
\hline & & Large quantitative range & \\
\hline & & Accurate data in fixed tissues & \\
\hline \multirow[t]{2}{*}{ Microarray } & medium & Some array are commercially & Complex analysis \\
\hline & & available & Results need PCR validation \\
\hline \multirow[t]{5}{*}{ Next generation Sequencing } & Medium to High & Independent of genome & High cost prevent the use of \\
\hline & & annotation & biological replicates \\
\hline & & (Discovery of novel splicing & Long multi-step procedure \\
\hline & & isoforms) & Complex analysis \\
\hline & & & Results need PCR validation \\
\hline
\end{tabular}

Table 1. Techniques used for the detection of alternative splicing 
Back in the 1980's, splicing isoforms were mainly detected by Northern-Blot, which separate transcripts by size [42] and estimate relative mRNA abundance using internal controls. However, this method is difficult to adopt in a clinical setting and require a large amount of RNA $(\mu \mathrm{g})$, which is difficult to obtain from clinical samples. Later, the discovery of reverse transcription and PCR amplification greatly facilitated the detection of splice variants [43]. Splicing isoform amplification is achived by using PCR primers that are designed to hybridize to constitutive exons flanking the ASE of interest (Fig. 4A). The products are separated in agarose gels or capillary gel electrophoresis [44] and the ratio of the long and short isoform quantified and presented as $\psi$ (percent of splicing index): the molarity of the long over the sum of the long and the short isoforms (Fig. 4A). Even if competitive PCR reaction are limited to a narrow range $[43,45]$, endpoint PCR is still the preferred technique to detect splicing isoforms due to the ease of use and low cost of the experiments.

The gold standard for the mRNA quantification is real-time PCR [46], which unlike standard endpoint PCR, detects the amount of products accumulating after each cycle of amplification and permits accurate comparison of different samples. This type of PCR requires the use of fluorescent probes [47] or dyes [48] that permit detection by specialized sensors. Despite the accuracy of this detection method it is rarely used for the detection of splice variants due to difficulty in achieving isoform specific amplification [43,49]. Primers required for the amplification of the short isoform need to bind to a short unique sequence created by the exon-exon junction, which severely restrict the design (Fig. 4B). However, systematic evaluation of isoform specific design parameters and the availability of new algorithms for primer selection greatly facilitated the detection of ASEs from any species [49]. Indeed, universal PCR conditions and ease of primer design makes real-time PCR reaches the point where it can compete with high-throughput detection methods like microarray in term of ASE coverage [49].

Microarray as a method for genome-wide expression profiling was discovered in 1995 [50], but the use of this method to detect splice variants was reported only in 2003 [51]. It took 8 years to develop methods that could distinguish between the hybridization patterns of two closely related transcripts and develop chips with high enough density to accommodate the thousands of splicing isoforms [51] (Fig. 4C) Early attempts to extract splicing pattern from expression microarrays generated high false positive rate [52]. Therefore, strategies where developed to probe exon-exon junction (junction array) [51]. In this case, alternative exons are defined by very low or very high signals emanating from two consecutive splice junctions [51]. Another popular strategy is to use exonic probe in addition to exon-exon junction probe (exon/junction array) [53]. In every case, the high similarity of exon-exon junction to favor non-specific hybridization and in some analysis procedures the information is restricted to splicing isoform "detection" rather than true quantification [54]. The most successful quantification of splicing isoform by microarray was achieved by relying solely on exonic probe [54-56]. However, the success of this method was limited by its dependence on a small set of pre-selected splice variants $[53,57]$. To allow the discovery of new splicing isoforms, a fourth strategy that consider all putative exons (tiling array) was developed [58]. However, the high number of probe required for this methods restricted coverage to only a 
small fraction of the genome. Not surprisingly, these difficulties hampered the application of this method for the study of ovarian cancer splicing isforms. Indeed, to date there is no report of microarray based profiling of ovarian cancer splice variants.

In theory, the most promising approach for the detection of ovarian cancer splicing isoform is the transcriptome sequencing [39]. Next generation sequencing (NGS) technology provide massively parallel sequencing of nucleotidic sequences in miniaturized microsystem. Several platforms are commercially available and their unique technology are discussed elsewhere [59,60]. The specific application of mRNA quantification through sequencing (RNA-seq) was demonstrated for different cancer types (e.g. lung [61] and prostate [62]) but not ovarian cancer thus far. Encouraging development in the refinement of the analytical pipeline to allow accurate quantification of splicing isoforms was recently made $[37,63,64]$. However, the complexity of the analytical pipeline of sequencing data and the cost of the sequencing read necessary to detect splice variants will reduce the speed by which this technique is applied to the discovery of splicing dependent biomarkers (Fig. 4D). In addition, secondary techniques like PCR will still be needed to confirm and validate the accuracy of the data generated and confirm it in a large number of clinical sample. Indeed, the majority of the AS information in ovarian cancer are derived from PCRbased techniques (see Table 2 and 3).

A

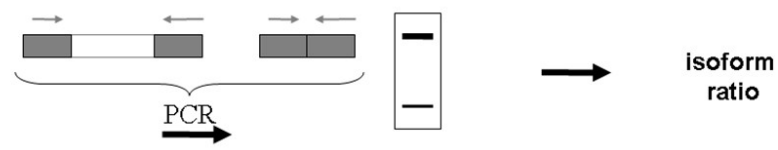

B

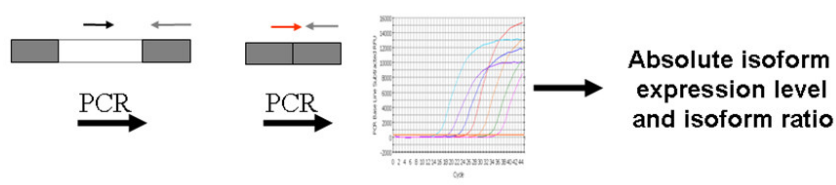

C

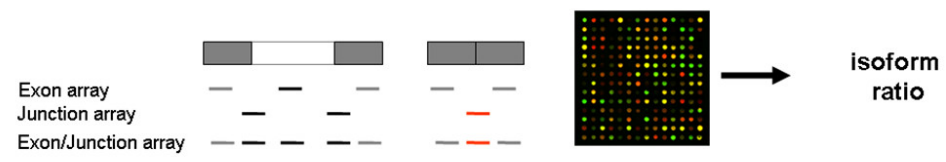

D

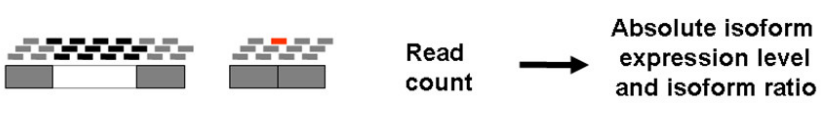

Figure 4. Methodology for splicing isoforms detection. A) Endpoint PCR. B) Real-time PCR. C) Microarray. D) Next Generation Sequencing. Red arrows and lines refer to short isoform specific detection. Gray boxes = constitutive exons; white boxes $=$ alternative exons. 


\begin{tabular}{|c|c|c|c|}
\hline Gene & Technique & Marker type and isoform description & Reference \\
\hline $\mathrm{BRCA} 1 / 2$ & $\begin{array}{l}\text { Endpoint } \\
\text { RT-PCR }\end{array}$ & $\begin{array}{l}\text { Prognosis } \\
\text { Numerous DNA mutation inactivated BRCA1/2 function } \\
\text { (deletion of essential domain or protein truncation) through } \\
\text { aberrant splicing. }\end{array}$ & {$[67]$} \\
\hline $\begin{array}{l}\text { RUNX1 } \\
\text { (AML1) }\end{array}$ & $\begin{array}{l}\text { Real-time } \\
\text { RT-PCR }\end{array}$ & $\begin{array}{l}\text { Prognosis } \\
\text { AML1 } 1 b^{\text {Del179-242 expression inversely }} \\
\text { correlates with overall survival }\end{array}$ & [69] \\
\hline KLF6 & $\begin{array}{l}\text { Real-time } \\
\text { RT-PCR }\end{array}$ & $\begin{array}{l}\text { Grade } \\
\text { The ratio of total to full length KLF6 expression correlates with } \\
\text { ovarian tumor grade }\end{array}$ & [72] \\
\hline TP53 & $\begin{array}{l}\text { Real-time } \\
\text { RT-PCR }\end{array}$ & $\begin{array}{l}\text { Chemoresistance } \\
\text { p53ठ expression is associated to impaired response to first line } \\
\text { chemotherapy }\end{array}$ & {$[75]$} \\
\hline FBLN1 & $\begin{array}{l}\text { Endpoint } \\
\text { RT-PCR }\end{array}$ & $\begin{array}{l}\text { Diagnosis } \\
\text { *The ratio of Fibulin C/D increase in ovarian tumors }\end{array}$ & {$[77]$} \\
\hline SPP1 & $\begin{array}{l}\text { Real-time } \\
\text { RT-PCR }\end{array}$ & $\begin{array}{l}\text { Diagnosis } \\
{ }^{*} \text { Osteopontin-c is undetectable in normal ovaries and present } \\
\text { in ovarian tumors }\end{array}$ & [85] \\
\hline
\end{tabular}

*Potential serum marker

Table 2. Ovarian cancer splicing markers discovered through single gene analysis

\begin{tabular}{|c|c|c|c|}
\hline Number of ASEs & Technique & Marker type and splicing signature description & Reference \\
\hline \multirow[t]{4}{*}{48 ASES } & Endpoint & Diagnosis & {$[44]$} \\
\hline & RT-PCR & This signature distinguishes normal ovaries from ovarian & \\
\hline & & tumors regardless of grade, stage or histotype (serous, & \\
\hline & & muscinous, endometriod, mix type) & \\
\hline \multirow[t]{3}{*}{288 ASES } & Endpoint & Diagnosis & {$[36]$} \\
\hline & RT-PCR & This signature distinguishes normal ovaries from serous high & \\
\hline & & grade ovarian tumors. & \\
\hline \multirow[t]{4}{*}{8 ASES } & Real-time & Diagnosis & {$[84]$} \\
\hline & RT-PCR & This cancer epithelial signature (CES) distinguishes normal & \\
\hline & & Fallopian tube epithelium tissues from ovarian epithelial & \\
\hline & & cancer cells & \\
\hline \multirow[t]{4}{*}{10 ASES } & Real-time & Diagnosis & {$[84]$} \\
\hline & RT-PCR & This cancer stromal signature (CSS) distinguishes normal & \\
\hline & & tissues from ovarian tumors independent of the epithelial & \\
\hline & & content of the tissue compared & \\
\hline
\end{tabular}

Table 3. Ovarian cancer splicing markers derived from high-throughput expression profiling. 


\section{Example of alternative splicing based ovarian cancer biomarkers}

\subsection{Gene specific discovery of splicing markers}

PCR-based techniques of specific genes associated with ovarian cancer revealed a number of ovarian cancer associated splicing events. The most promising of these potential biomarkers for diagnosis, prognosis, chemoresistance and grade biomarkers are listed in table 2 and are further described in the text below.

BRCA1/2. The ability of DNA mutation in the hereditary gene BRCA1 and BRCA2 (BRCA1/2) to predict the risk of ovarian and breast cancer is known for decades $[65,66]$. However, in several instance, the clinical relevance of DNA mutation is unknown, making the clinical management difficult to establish properly. Furthermore, the role of these mutations in varying the splicing of BRCA genes was largely ignored despite the fact that any nucleotide changes in the splice site consensus sequences or in any AS regulatory sequence could produce aberrant splicing isoforms. Recently, in vitro splicing assay of BRCA1/2 mutation [67], revealed that many cancer associated variants including those with unsuspected synonymous mutations have dramatic effect on splicing. Strikingly, six of the most frequent DNA variants representing 58,5\% of BRCA1 families induced aberrant splicing profile [67]. These results, clearly demonstrate the importance of studying cancer associated splicing since it may in many case help explain mutation that cannot be associated with changes in protein sequence. However, the fidelity of splicing signature as a diagnostic marker as compared to DNA sequencing remains to be established.

RUNX1. Runt-related transcription factor 1 is a transcriptional regulator harboring a DNAbinding runt homology domain (RHD). Several layers of regulation (transcription, splicing and translation) fine-tune its tissue-specific expression [68]. RUNX1 is also known as Acute myeloid leukemia (AML) 1 and is often found as oncogenic fusion in leukemia. Nanjundan $\mathrm{M}$ and collaborators [69] report the fortuit discovery of a novel isoform that lack exon 6 as compared to isoform AML1b during classical cloning procedure. This novel isoform, subsequently named AML1b $b^{\text {Del179-242 }}$ was found to be the dominant isoform in the majority of the 42 ovarian tumors studied. Functionally speaking, skipping of exon 6 severely abrogated the transactivation potential of the resulting protein and inhibits its tumor suppressive functions. Interestingly, AML1b $b^{\text {Del179-242 }}$ level was either not different from normal cell line (lung cancer) or significantly decreased (breast cancer), suggesting that it may be an ovarian specific marker [69]. Noneoftheless, AML1b ${ }^{\text {Del179-242 }}$ expression is inversely proportional to the survival rate of patient, suggesting is used as a prognosis marker [69]. As attractive as it sounds, AML1b ${ }^{\text {Del179-242 }}$ certainly represent an excellent potential target and marker but required further validation in larger cohort and by independent research group.

KLF6. Kruppel-like factor (KLF) 6 is a transcription factor from the well conserved KLF gene family implicated in differentiation, development and cell growth [70,71]. KLF6 is a suspected tumor suppressor gene in several epithelial cancer (see [72] and reference there in). In ovarian cancer, an increase in KLF6 isoforms was noted and correlates with the aggressivity of the tumor in tissues (grade). One of these isoform is produced by the use of the more dis- 
tal alt5' ss and produce a protein version lacking the characteristic zinc finger binding domain (KLF6 SV1) and act as a dominant-negative [72]. Although the technical challenges of amplifying specific KLF6 isoforms preclude pinpointing the KLF6 SV1 as the isoform that correlates with grade tumor, a series of in vitro and in vivo evidence making it likely [72]. It remains to be established whether or not the full length KLF6 over KLF6 SV1 isoform ratio could serve as a prognosis or even early marker.

TP53. The tumor suppressor gene TP53 is mutated in several solid tumors and in almost all of the serous ovarian tumors [73]. Mutations affecting splice site of TP53 are very common [74] and leads to a complex pattern of splicing isoforms that add up to the already complex picture of this gatekeeper. Indeed, the point mutation IVS9-2A>G destroys the splice acceptor and redirect the splicing to include exon 9c. The resulting p538 protein isoform is truncated in the oligomerization domain and have a new stretch of 27 new residues. In a cohort of 245 ovarian samples, the expression of this isoform is significantly correlated with poor overall survival in multivariate analyses. Moreover, patient having tumor that express p538 have a higher chance of early relapse after first-line chemotherapy [75]. Since isoform p53ठ doesn't correlate with the debulking status, it suggests that expression of p538 impair platinum-based chemotherapy [75]. In respect to personalized medicine, it would be very inter-

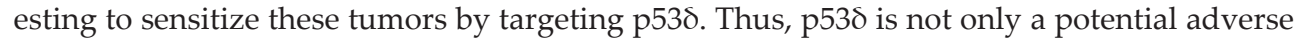
prognosis marker but could also be a promising target for a subclass of ovarian tumors.

FBLN1. Fibulin (FBLN) 1 is an extracellular matrix (ECM)-associated protein produced by both stromal cells and epithelial cells [76]. Its presence near sites of epithelial cells locally invading stromal boundaries suggests its implication in cell adhesion/motility (see [77] and reference there in). Different C-terminal exons of the FBLN1 gene are alternatively spliced to generate four isoforms. In ovarian tumors, the ratio fibulin $1 \mathrm{C} /$ fibulin $1 \mathrm{D}$ is significantly increased compared to benign ovarian cystic sample [77]. Interestingly, the isoform ratio between normal and benign cyst is slightly increased in cystic samples (although not significant). It raises the hypothesis that the ratio fibulin $1 \mathrm{C} /$ fibulin $1 \mathrm{D}$ could potentially serves as an early diagnostic marker. Importantly, the sensitivity and specificity of fibulin splicing isoforms remains to be firmly established using a panel of normal and early lesion tissues and ultimately in patient's serum.

SPP1. Osteopontin is a member of the small integrin-binding ligand, N-linked glycoprotein (SIBLING) family of proteins [78]. It is an important component of the ECM that is secreted by both cancer cells and stromal cells in the tumor microenvironment [79]. Osteopontin interacts with various integrin receptors $[80,81]$ as well as the CD44 receptor [82] to activate the angiogenic switch or enhance cancer cell motility [79]. The level of osteopontin is elevated in patient's plasma when compared to healthy controls by enzyme-linked immuno assay (ELISA) [83]. However, the specificity $(80,4 \%)$ and sensitivity $(80,4 \%)$ for the detection of early stage disease are not convincing [83]. These parameters could be increase if one takes advantages of AS. A recent report conducted by real-time PCR indicated that the isoform osteopontin c (excluding exon 4) is absent in normal or benign tissues but always present in ovarian cancer samples. This is supported by our own data from microdissected normal and cancerous ovarian cells indicating that the expression of osteopontin c comes specifically 
from ovarian epithelial cancer cells [84]. Conditioned medium overexpressing osteopontin c stimulate proliferation of cancer cells more efficiently than either osteopontin $a$ or $b$, and this effect is revert by specific antibodies against osteopontin c [85]. Based on these data, the biomarker capacity of osteopontin in patient's blood need to be re-established using isoformspecific methodology. As the secretion of osteopontin might be an early event [86-88], it is tempting to speculate that osteopontin c could be an early marker.

\subsection{Splicing markers generated through genome-wide expression profiling}

The advent of splicing sensitive high-throughput technique opens the doors to monitor a large number of randomly selected ASEs rather than be limited to few candidate genes (see Table 3). The recent use of high-throughput RT-PCR by coupling PCR reaction in 384 wells plate to capillary gel electrophoresis in 96 well Caliper station dramatically increased the number of confirmed ovarian cancer associated splicing events. Initially, exon-exon junctions were systematically analyzed for a set of 600 cancer related genes in four different pools of normal and cancer ovarian samples. The resulting ASEs were subsequently validated using an independent set of 21 normal ovaries and 25 ovarian cancer samples, yielding 48 ASE markers [44]. Later on, a focus on a collection of 2168 highly curated ASEs (RefSeq NCBI build 36) subsequently yield 288 ASEs markers using roughly the same sample set [36]. The relatively high number of ASEs markers found coupled to the fact that several were related to the epithelial-mesenchymal transition raised the possibility that a large fraction of the discovered events might result from difference in the cell type compared (normal ovaries are largely composed of stromal cells where as ovarian tumors have a typical epithelial content around 75\% [36]). This question was answered when 9 ovarian tumors were microdissected to isolated the RNA from stromal (tumor microenvironment) and epithelial cancer cells separately. A real-time PCR-based screening strategy coupled to an update version of RefSeq NCBI build 36 (3313 ASEs) yield a low but unambiguous set of cancer-specific splicing isoforms, the cancer epithelial signature (CES) [84]. Surprisingly, the tumor microenvironment appears to contain promising splicing isoforms RNA markers. Indeed, this cancer stromal signature (CSS) might be able to diagnosis early ovarian tumors as it clusters low malignant potential and low-grade tumors within normal ovaries and Fallopian tube samples, although this study was performed on a low number of tissues [84].

The possibility that ovarian tumor microenvironment may be a source of splicing isoforms markers raise interesting questions regarding the studies conducted on whole tumors. First, some of the RNA transcripts detected may actually come from the microenvironment cells. For exemple, fibulin and fibronectin are two ECM components known to be produced and secreted by stromal cells. Pinpointing the cell type that produced those splicing deregulated secreted proteins will certainly help to rationalize the complex autocrine and paracrine pathways implicated in the cell to cell communication that take place into and surrounding the ovarian tumor. Second, AS is a highly tissue-specific process, some of the splicing pattern changes might be the reflection of the different proportion of stromal and epithelial cells of ovarian tumors. Theoretically, those effects would be minimal when ovarian tumors of equivalent epithelial content (typically 50-75\%) are compared but maximal when normal 
ovaries (1\% epithelial cells) are used as normal reference. As a consequence, prognosis marker derived from cancer samples comparison should yield more reliable splicing markers than diagnosis marker normalized with normal ovaries.

\subsection{Alternative splicing associated protein markers}

Interestingly, a number of RNA splicing isoforms markers might be amenable to detection at the protein level using isoform-specific antibodies. Ultimately, these could serve as diagnostic or prognostic tool to either directly detect the presence of cancer cells or indirectly the protein in patient's fluid. Indeed, the product of the genes encoding fibronectin 1, fibulin, osteopontin, galectin 9, platelet derived growth factor A, extracellular sulfatase 2 and slit homolog 2 are all secreted in the extracellular matrix. Even some cytosolic proteins such as utrophin and serine hydroxymethyltransferase 1 were found in patient's serum [89]. Others are cell surface protein (amyloid beta A4 protein, stromal interaction molecule 1, CD97, peptidyl-glycine alpha-amidating monooxygenase and chemokine-like factor) harboring an ASE that encodes for an extracellular domain. More impressively, the exon encoding the transmembrane domain of betacellulin is preferentially excluded in ovarian tumors [44], leading to a secreted version of the protein [90]. Thus in every cases, isoform-specific antibodies could be theoretically raised against the cancer associated isoform to ultimately serve as diagnostic/prognostic tool to either detect cancer cells or detect the protein in patient's fluid.

Inversely, the splicing isoforms of the cell surface receptor Fas and CD44 were mostly studied at the protein level by either immunohistochemistry (IHC) or ELISA. Fas linked extracellular apoptotic signals that converge to the programmed cell death pathway through caspase 8 and 10. Differential usage of exon 6, which encodes the single pass transmembrane domain, results in a soluble version (sFas) and a membrane anchored version (mFas). The level of sFas is increase in ovarian tumor of higher grade compared to low grade [91,92] and correlates with worst prognosis for these patient [91]. Although these studies were performed in small cohort, it elegantly demonstrated that AS can produce isoforms detectable in patient's serum.

The glycoprotein CD44 is a cell surface receptor that binds diverse extracellular matrix ligands such as hyaluronic acid, fibronectin, osteopontin, collagen and laminin [93]. The binding of low molecular weight hyaluronan polymer promotes the motility and invasion properties of CD44 (review in [93]). It is encoded as a 20 exons gene that exhibit extensive AS of the extracellular domain of exons 6 to 15 (also called variable exons 1 to 10). The major isoform present in normal epithelial [94,95] or stromal [96] ovarian cells is the shorter isoform CD44s lacking all variable exons (CD44s for standard isoform). In contrast, a complex pattern of splicing isoforms were detected in cancer tissues, including most of ovarian tumors by mean of RT-PCR $[94,97,98]$ or by IHC using isoform specific antibodies $[95,96,99,100]$. One of these splicing isoforms, the inclusion of exon v10, appears to correlate with prognosis and is indicative of improved survival in a multivariate analysis of a 142 patient cohort by IHC [96]. However, these findings contrast the initial study of Schroder who found no exon v10 expression although it relies on a smaller cohort [100]. Intriguingly, inclusion of exon v10 in metastatic tumors was correlated with decrease survival [96]. This ap- 
parent discrepancy could be rationalized if the exon v10 inclusion is seen as crucial to maintain proper cell adhesion and avoid cell detachment [101]. It remains to be determined if any of the variable exons of CD44 could serve as biomarker at the RNA level.

\section{Concluding remarks}

AS dramatically increase the diversity of protein expression in human cells and therefore exponentially increase the number of potential disease markers. However, the complexity in detecting AS and the unclear function of the majority of splice variants greatly reduced the rate of AS based ovarian cancer biomarkers. This trend is likely to change in the next few years with the explosion of whole transcriptome sequencing efforts and the inevitable identification of splice variants as byproducts of next generations' expression profiles. The real challenge now is to develop techniques allowing the use of splicing markers in the clinic and prepare pathologists to this new wave. Clearly, a compelling argument is needed to drive this drastic change in clinical practice and it will most likely be driven by the success of AS based screens in rationally predicting secreted protein that may serve as non-invasive ovarian cancer markers.

\section{Author details}

Jean-Philippe Brosseau ${ }^{1,2}$ and Sherif Abou-Elela ${ }^{1,3}$

*Address all correspondence to: sherif.abou.elela@usherbrooke.ca

1 Laboratoire de Génomique Fonctionnelle de l’Université de Sherbrooke, Canada

2 Département de Biochimie, Faculté de Médecine et des Sciences de la Santé, Université de Sherbrooke, Sherbrooke, Québec, Canada

3 Département de Microbiologie et d'Infectiologie, Faculté de Médecine et des Sciences de la Santé, Université de Sherbrooke, Sherbrooke, Québec, Canada

\section{References}

[1] Statistiques canadiennes sur le cancer. Available at: http://www.cancer.ca.

[2] Herbst AL. The epidemiology of ovarian carcinoma and the current status of tumor markers to detect disease. Am J Obstet Gynecol 1994 Apr;170(4):1099-105; discussion 1105-7. 
[3] Bast RC,Jr, Klug TL, St John E, Jenison E, Niloff JM, Lazarus H, et al. A radioimmunoassay using a monoclonal antibody to monitor the course of epithelial ovarian cancer. N Engl J Med 1983 Oct 13;309[15]:883-887.

[4] Skates SJ, Jacobs IJ, Knapp RC. Tumor markers in screening for ovarian cancer. In: Bartlett JMS, editor. Ovarian Cancer: Methods and Protocols Totowa, NJ, USA: Humana Press; 2000. p. 61-73.

[5] Muller CY. Doctor, should I get this new ovarian cancer test-OVA1? Obstet Gynecol 2010 Aug;116[2 Pt 1]:246-247.

[6] Bast RC,Jr, Badgwell D, Lu Z, Marquez R, Rosen D, Liu J, et al. New tumor markers: CA125 and beyond. Int J Gynecol Cancer 2005 Nov-Dec;15 Suppl 3:274-281.

[7] Diaz-Padilla I, Razak AR, Minig L, Bernardini MQ, Maria Del Campo J. Prognostic and predictive value of CA-125 in the primary treatment of epithelial ovarian cancer: potentials and pitfalls. Clin Transl Oncol 2012 Jan;14(1):15-20.

[8] Konstantinopoulos PA, Spentzos D, Cannistra SA. Gene-expression profiling in epithelial ovarian cancer. Nat Clin Pract Oncol 2008 Oct;5[10]:577-587.

[9] Fekete T, Raso E, Pete I, Tegze B, Liko I, Munkacsy G, et al. Meta-analysis of gene expression profiles associated with histological classification and survival in 829 ovarian cancer samples. Int J Cancer 2012 Jul 1;131(1):95-105.

[10] Callesen AK, Mogensen O, Jensen AK, Kruse TA, Martinussen T, Jensen ON, et al. Reproducibility of mass spectrometry based protein profiles for diagnosis of ovarian cancer across clinical studies: A systematic review. J Proteomics 2012 Jun 6;75[10]: 2758-2772.

[11] Anderson NL. The clinical plasma proteome: a survey of clinical assays for proteins in plasma and serum. Clin Chem 2010 Feb;56(2):177-185.

[12] Topisirovic I, Svitkin YV, Sonenberg N, Shatkin AJ. Cap and cap-binding proteins in the control of gene expression. Wiley Interdiscip Rev RNA 2011 Mar-Apr;2(2): 277-298.

[13] Will CL, Luhrmann R. Spliceosome structure and function. Cold Spring Harb Perspect Biol 2011 Jul 1;3(7):10.1101/cshperspect.a003707.

[14] Lutz CS. Alternative polyadenylation: a twist on mRNA 3' end formation. ACS Chem Biol 2008 Oct 17;3[10]:609-617.

[15] Oeffinger M, Zenklusen D. To the pore and through the pore: A story of mRNA export kinetics. Biochim Biophys Acta 2012 Jun;1819(6):494-506.

[16] Aitken CE, Lorsch JR. A mechanistic overview of translation initiation in eukaryotes. Nat Struct Mol Biol 2012 Jun 5;19(6):568-576.

[17] Black DL. Mechanisms of alternative pre-messenger RNA splicing. Annu Rev Biochem 2003;72:291-336. 
[18] Krummel DA, Nagai K, Oubridge C. Structure of spliceosomal ribonucleoproteins. F1000 Biol Rep 2010 May 24;2:39.

[19] Wang ET, Sandberg R, Luo S, Khrebtukova I, Zhang L, Mayr C, et al. Alternative isoform regulation in human tissue transcriptomes. Nature 2008 Nov 27;456[7221]: $470-476$.

[20] Lewis BP, Green RE, Brenner SE. Evidence for the widespread coupling of alternative splicing and nonsense-mediated mRNA decay in humans. Proc Natl Acad Sci U S A 2003 Jan 7;100(1):189-192.

[21] Garneau NL, Wilusz J, Wilusz CJ. The highways and byways of mRNA decay. Nat Rev Mol Cell Biol 2007 Feb;8(2):113-126.

[22] Hughes TA. Regulation of gene expression by alternative untranslated regions. Trends Genet 2006 Mar;22(3):119-122.

[23] Zhang $\mathrm{XH}$, Chasin LA. Computational definition of sequence motifs governing constitutive exon splicing. Genes Dev 2004 Jun 1;18[11]:1241-1250.

[24] Fairbrother WG, Yeh RF, Sharp PA, Burge CB. Predictive identification of exonic splicing enhancers in human genes. Science 2002 Aug 9;297[5583]:1007-1013.

[25] Graveley BR. Sorting out the complexity of SR protein functions. RNA 2000 Sep;6(9): 1197-1211.

[26] Zhu J, Mayeda A, Krainer AR. Exon identity established through differential antagonism between exonic splicing silencer-bound hnRNP A1 and enhancer-bound SR proteins. Mol Cell 2001 Dec;8(6):1351-1361.

[27] Tange TO, Damgaard CK, Guth S, Valcarcel J, Kjems J. The hnRNP A1 protein regulates HIV-1 tat splicing via a novel intron silencer element. EMBO J 2001 Oct 15;20[20]:5748-5758.

[28] Martinez-Contreras R, Fisette JF, Nasim FU, Madden R, Cordeau M, Chabot B. Intronic binding sites for hnRNP A/B and hnRNP F/H proteins stimulate pre-mRNA splicing. PLoS Biol 2006 Feb;4(2):e21.

[29] Mayeda A, Krainer AR. Regulation of alternative pre-mRNA splicing by hnRNP A1 and splicing factor SF2. Cell 1992 Jan 24;68(2):365-375.

[30] Eperon IC, Makarova OV, Mayeda A, Munroe SH, Caceres JF, Hayward DG, et al. Selection of alternative 5' splice sites: role of U1 snRNP and models for the antagonistic effects of SF2/ASF and hnRNP A1. Mol Cell Biol 2000 Nov;20[22]:8303-8318.

[31] Yeo GW, Van Nostrand EL, Liang TY. Discovery and analysis of evolutionarily conserved intronic splicing regulatory elements. PLoS Genet 2007 May 25;3(5):e85.

[32] Voelker RB, Berglund JA. A comprehensive computational characterization of conserved mammalian intronic sequences reveals conserved motifs associated with constitutive and alternative splicing. Genome Res 2007 Jul;17(7):1023-1033. 
[33] Kalsotra A, Xiao X, Ward AJ, Castle JC, Johnson JM, Burge CB, et al. A postnatal switch of CELF and MBNL proteins reprograms alternative splicing in the developing heart. Proc Natl Acad Sci U S A 2008 Dec 23;105[51]:20333-20338.

[34] Warzecha CC, Jiang P, Amirikian K, Dittmar KA, Lu H, Shen S, et al. An ESRP-regulated splicing programme is abrogated during the epithelial-mesenchymal transition. EMBO J 2010 Oct 6;29[19]:3286-3300.

[35] Zhang C, Frias MA, Mele A, Ruggiu M, Eom T, Marney CB, et al. Integrative modeling defines the Nova splicing-regulatory network and its combinatorial controls. Science 2010 Jul 23;329[5990]:439-443.

[36] Venables JP, Klinck R, Koh C, Gervais-Bird J, Bramard A, Inkel L, et al. Cancer-associated regulation of alternative splicing. Nat Struct Mol Biol 2009 Jun;16(6):670-676.

[37] Katz Y, Wang ET, Airoldi EM, Burge CB. Analysis and design of RNA sequencing experiments for identifying isoform regulation. Nat Methods 2010 Dec;7[12]: 1009-1015.

[38] Prinos P, Garneau D, Lucier JF, Gendron D, Couture S, Boivin M, et al. Alternative splicing of SYK regulates mitosis and cell survival. Nat Struct Mol Biol 2011 Jun; 18(6):673-679.

[39] Pan Q, Shai O, Lee LJ, Frey BJ, Blencowe BJ. Deep surveying of alternative splicing complexity in the human transcriptome by high-throughput sequencing. Nat Genet 2008 Dec;40[12]:1413-1415.

[40] Bouanene H, Miled A. Tumor Marker CA125: biochemical and molecular properties. Bull Cancer 2009 May;96(5):597-601.

[41] Mittendorf KF, Deatherage CL, Ohi MD, Sanders CR. Tailoring of Membrane Proteins by Alternative Splicing of Pre-mRNA. Biochemistry 2012 Jun 29.

[42] Cheng C, Sharp PA. Regulation of CD44 alternative splicing by SRm160 and its potential role in tumor cell invasion. Mol Cell Biol 2006 Jan;26(1):362-370.

[43] Bracco L, Throo E, Cochet O, Einstein R, Maurier F. Methods and platforms for the quantification of splice variants' expression. Prog Mol Subcell Biol 2006;44:1-25.

[44] Klinck R, Bramard A, Inkel L, Dufresne-Martin G, Gervais-Bird J, Madden R, et al. Multiple alternative splicing markers for ovarian cancer. Cancer Res 2008 Feb 1;68(3): 657-663.

[45] Richards MP, Poch SM. Quantitative analysis of gene expression by reverse transcription polymerase chain reaction and capillary electrophoresis with laser-induced fluorescence detection. Mol Biotechnol 2002 May;21(1):19-37.

[46] Nolan T, Hands RE, Bustin SA. Quantification of mRNA using real-time RT-PCR. Nat Protoc 2006;1(3):1559-1582. 
[47] Heid CA, Stevens J, Livak KJ, Williams PM. Real time quantitative PCR. Genome Res 1996 Oct;6[10]:986-994.

[48] Morrison TB, Weis JJ, Wittwer CT. Quantification of low-copy transcripts by continuous SYBR Green I monitoring during amplification. BioTechniques 1998 Jun;24(6): 954-8, 960, 962.

[49] Brosseau JP, Lucier JF, Lapointe E, Durand M, Gendron D, Gervais-Bird J, et al. High-throughput quantification of splicing isoforms. RNA 2010 Feb;16(2):442-449.

[50] Schena M, Shalon D, Davis RW, Brown PO. Quantitative monitoring of gene expression patterns with a complementary DNA microarray. Science 1995 Oct 20;270[5235]: 467-470.

[51] Johnson JM, Castle J, Garrett-Engele P, Kan Z, Loerch PM, Armour CD, et al. Genome-wide survey of human alternative pre-mRNA splicing with exon junction microarrays. Science 2003 Dec 19;302[5653]:2141-2144.

[52] Hu GK, Madore SJ, Moldover B, Jatkoe T, Balaban D, Thomas J, et al. Predicting splice variant from DNA chip expression data. Genome Res 2001 Jul;11(7):1237-1245.

[53] Pan Q, Shai O, Misquitta C, Zhang W, Saltzman AL, Mohammad N, et al. Revealing global regulatory features of mammalian alternative splicing using a quantitative microarray platform. Mol Cell 2004 Dec 22;16(6):929-941.

[54] Cuperlovic-Culf M, Belacel N, Culf AS, Ouellette RJ. Data analysis of alternative splicing microarrays. Drug Discov Today 2006 Nov;11[21-22]:983-990.

[55] Gardina PJ, Clark TA, Shimada B, Staples MK, Yang Q, Veitch J, et al. Alternative splicing and differential gene expression in colon cancer detected by a whole genome exon array. BMC Genomics 2006 Dec 27;7:325.

[56] Clark TA, Schweitzer AC, Chen TX, Staples MK, Lu G, Wang H, et al. Discovery of tissue-specific exons using comprehensive human exon microarrays. Genome Biol 2007;8(4):R64.

[57] Fagnani M, Barash Y, Ip JY, Misquitta C, Pan Q, Saltzman AL, et al. Functional coordination of alternative splicing in the mammalian central nervous system. Genome Biol 2007;8(6):R108.

[58] Bertone P, Stolc V, Royce TE, Rozowsky JS, Urban AE, Zhu X, et al. Global identification of human transcribed sequences with genome tiling arrays. Science 2004 Dec 24;306[5705]:2242-2246.

[59] Metzker ML. Sequencing technologies - the next generation. Nat Rev Genet 2010 Jan; 11(1):31-46.

[60] Pareek CS, Smoczynski R, Tretyn A. Sequencing technologies and genome sequencing. J Appl Genet 2011 Nov;52(4):413-435.

[61] Kalari KR, Rossell D, Necela BM, Asmann YW, Nair A, Baheti S, et al. Deep Sequence Analysis of Non-Small Cell Lung Cancer: Integrated Analysis of Gene Expression, 
Alternative Splicing, and Single Nucleotide Variations in Lung Adenocarcinomas with and without Oncogenic KRAS Mutations. Front Oncol 2012;2:12.

[62] Wu Y, Wang X, Wu F, Huang R, Xue F, Liang G, et al. Transcriptome profiling of the cancer, adjacent non-tumor and distant normal tissues from a colorectal cancer patient by deep sequencing. PLoS One 2012;7(8):e41001.

[63] Ameur A, Wetterbom A, Feuk L, Gyllensten U. Global and unbiased detection of splice junctions from RNA-seq data. Genome Biol 2010;11(3):R34.

[64] Anders S, Reyes A, Huber W. Detecting differential usage of exons from RNA-seq data. Genome Res 2012 Jun 21.

[65] Miki Y, Swensen J, Shattuck-Eidens D, Futreal PA, Harshman K, Tavtigian S, et al. A strong candidate for the breast and ovarian cancer susceptibility gene BRCA1. Science 1994 Oct 7;266[5182]:66-71.

[66] Wooster R, Bignell G, Lancaster J, Swift S, Seal S, Mangion J, et al. Identification of the breast cancer susceptibility gene BRCA2. Nature 1995 Dec 21-28;378[6559]: 789-792.

[67] Sanz DJ, Acedo A, Infante M, Duran M, Perez-Cabornero L, Esteban-Cardenosa E, et al. A high proportion of DNA variants of BRCA1 and BRCA2 is associated with aberrant splicing in breast/ovarian cancer patients. Clin Cancer Res 2010 Mar 15;16(6): 1957-1967.

[68] Levanon D, Bernstein Y, Negreanu V, Ghozi MC, Bar-Am I, Aloya R, et al. A large variety of alternatively spliced and differentially expressed mRNAs are encoded by the human acute myeloid leukemia gene AML1. DNA Cell Biol 1996 Mar;15(3): 175-185.

[69] Nanjundan M, Zhang F, Schmandt R, Smith-McCune K, Mills GB. Identification of a novel splice variant of AML1b in ovarian cancer patients conferring loss of wild-type tumor suppressive functions. Oncogene 2007 Apr 19;26[18]:2574-2584.

[70] Bieker JJ. Kruppel-like factors: three fingers in many pies. J Biol Chem 2001 Sep 14;276[37]:34355-34358.

[71] Black AR, Black JD, Azizkhan-Clifford J. Sp1 and kruppel-like factor family of transcription factors in cell growth regulation and cancer. J Cell Physiol 2001 Aug;188(2): 143-160.

[72] DiFeo A, Narla G, Hirshfeld J, Camacho-Vanegas O, Narla J, Rose SL, et al. Roles of KLF6 and KLF6-SV1 in ovarian cancer progression and intraperitoneal dissemination. Clin Cancer Res 2006 Jun 15;12[12]:3730-3739.

[73] Ahmed AA, Etemadmoghadam D, Temple J, Lynch AG, Riad M, Sharma R, et al. Driver mutations in TP53 are ubiquitous in high grade serous carcinoma of the ovary. J Pathol 2010 May;221(1):49-56. 
[74] Holmila R, Fouquet C, Cadranel J, Zalcman G, Soussi T. Splice mutations in the p53 gene: case report and review of the literature. Hum Mutat 2003 Jan;21(1):101-102.

[75] Hofstetter G, Berger A, Fiegl H, Slade N, Zoric A, Holzer B, et al. Alternative splicing of p53 and p73: the novel p53 splice variant p53delta is an independent prognostic marker in ovarian cancer. Oncogene 2010 Apr 1;29[13]:1997-2004.

[76] Roger P, Pujol P, Lucas A, Baldet P, Rochefort H. Increased immunostaining of fibulin-1, an estrogen-regulated protein in the stroma of human ovarian epithelial tumors. Am J Pathol 1998 Nov;153(5):1579-1588.

[77] Moll F, Katsaros D, Lazennec G, Hellio N, Roger P, Giacalone PL, et al. Estrogen induction and overexpression of fibulin-1C mRNA in ovarian cancer cells. Oncogene 2002 Feb 7;21(7):1097-1107.

[78] Bellahcene A, Castronovo V, Ogbureke KU, Fisher LW, Fedarko NS. Small integrinbinding ligand N-linked glycoproteins (SIBLINGs): multifunctional proteins in cancer. Nat Rev Cancer 2008 Mar;8(3):212-226.

[79] Ahmed M, Behera R, Chakraborty G, Jain S, Kumar V, Sharma P, et al. Osteopontin: a potentially important therapeutic target in cancer. Expert Opin Ther Targets 2011 Sep;15(9):1113-1126.

[80] Zheng W, Li R, Pan H, He D, Xu R, Guo TB, et al. Role of osteopontin in induction of monocyte chemoattractant protein 1 and macrophage inflammatory protein 1beta through the NF-kappaB and MAPK pathways in rheumatoid arthritis. Arthritis Rheum 2009 Jul;60(7):1957-1965.

[81] Yokosaki Y, Matsuura N, Sasaki T, Murakami I, Schneider H, Higashiyama S, et al. The integrin alpha(9)beta(1) binds to a novel recognition sequence (SVVYGLR) in the thrombin-cleaved amino-terminal fragment of osteopontin. J Biol Chem 1999 Dec 17;274[51]:36328-36334.

[82] Katagiri YU, Sleeman J, Fujii H, Herrlich P, Hotta H, Tanaka K, et al. CD44 variants but not CD44s cooperate with beta1-containing integrins to permit cells to bind to osteopontin independently of arginine-glycine-aspartic acid, thereby stimulating cell motility and chemotaxis. Cancer Res 1999 Jan 1;59(1):219-226.

[83] Kim JH, Skates SJ, Uede T, Wong KK, Schorge JO, Feltmate CM, et al. Osteopontin as a potential diagnostic biomarker for ovarian cancer. JAMA 2002 Apr 3;287[13]: 1671-1679.

[84] Brosseau JP, Lucier JF, Nwilati H, Thibault P, Durand M, Garneau D, et al. Programmed modulation of alternative splicing in the tumor microenvironment. submitted.

[85] Tilli TM, Franco VF, Robbs BK, Wanderley JL, da Silva FR, de Mello KD, et al. Osteopontin-c splicing isoform contributes to ovarian cancer progression. Mol Cancer Res 2011 Mar;9(3):280-293. 
[86] Mi Z, Bhattacharya SD, Kim VM, Guo H, Talbot LJ, Kuo PC. Osteopontin promotes CCL5-mesenchymal stromal cell-mediated breast cancer metastasis. Carcinogenesis 2011 Apr;32(4):477-487.

[87] McAllister SS, Gifford AM, Greiner AL, Kelleher SP, Saelzler MP, Ince TA, et al. Systemic endocrine instigation of indolent tumor growth requires osteopontin. Cell 2008 Jun 13;133(6):994-1005.

[88] Pazolli E, Luo X, Brehm S, Carbery K, Chung JJ, Prior JL, et al. Senescent stromal-derived osteopontin promotes preneoplastic cell growth. Cancer Res 2009 Feb 1;69(3): 1230-1239.

[89] Lomnytska M, Dubrovska A, Hellman U, Volodko N, Souchelnytskyi S. Increased expression of cSHMT, Tbx3 and utrophin in plasma of ovarian and breast cancer patients. Int J Cancer 2006 Jan 15;118(2):412-421.

[90] Dunbar AJ, Goddard C. Identification of an alternatively spliced mRNA transcript of human betacellulin lacking the C-loop of the EGF motif and the transmembrane domain. Growth Factors 2000;18(3):169-175.

[91] Konno R, Takano T, Sato S, Yajima A. Serum soluble fas level as a prognostic factor in patients with gynecological malignancies. Clin Cancer Res 2000 Sep;6(9): 3576-3580.

[92] Midis GP, Shen Y, Owen-Schaub LB. Elevated soluble Fas (sFas) levels in nonhematopoietic human malignancy. Cancer Res 1996 Sep 1;56[17]:3870-3874.

[93] Louderbough JM, Schroeder JA. Understanding the dual nature of CD44 in breast cancer progression. Mol Cancer Res 2011 Dec;9[12]:1573-1586.

[94] Cannistra SA, Abu-Jawdeh G, Niloff J, Strobel T, Swanson L, Andersen J, et al. CD44 variant expression is a common feature of epithelial ovarian cancer: lack of association with standard prognostic factors. J Clin Oncol 1995 Aug;13(8):1912-1921.

[95] Darai E, Walker-Combrouze F, Fauconnier A, Madelenat P, Potet F, Scoazec JY. Analysis of CD44 expression in serous and mucinous borderline tumours of the ovary: comparison with cystadenomas and overt carcinomas. Histopathology 1998 Feb; 32(2):151-159.

[96] Rodriguez-Rodriguez L, Sancho-Torres I, Mesonero C, Gibbon DG, Shih WJ, Zotalis G. The CD44 receptor is a molecular predictor of survival in ovarian cancer. Med Oncol 2003;20(3):255-263.

[97] Lee JH, Kang YS, Kim BG, Park SY, Lee ED, Lee KH, et al. Expression of the CD44 adhesion molecule in primary and metastatic gynecologic malignancies and their cell lines. Int J Gynecol Cancer 1995 May;5(3):193-199.

[98] Sanchez Lockhart M, Hajos SE, Basilio FM, Mongini C, Alvarez E. Splice variant expression of CD44 in patients with breast and ovarian cancer. Oncol Rep 2001 Jan-Feb; 8(1):145-151. 
[99] Uhl-Steidl M, Muller-Holzner E, Zeimet AG, Adolf GR, Daxenbichler G, Marth C, et al. Prognostic value of CD44 splice variant expression in ovarian cancer. Oncology 1995 Sep-Oct;52(5):400-406.

[100] Schroder W, Rudlowski C, Biesterfeld S, Knobloch C, Hauptmann S, Rath W. Expression of CD44(v5-10) splicing variants in primary ovarian cancer and lymph node metastases. Anticancer Res 1999 Sep-Oct;19(5B):3901-3906.

[101] Chiu RK, Droll A, Dougherty ST, Carpenito C, Cooper DL, Dougherty GJ. Alternatively spliced CD44 isoforms containing exon v10 promote cellular adhesion through the recognition of chondroitin sulfate-modified CD44. Exp Cell Res 1999 Apr 10;248(1):314-321. 